\title{
The Cardiothoracic Surgical Trials Network: Implications for clinical practice
}

\author{
Patrick T. O'Gara, MD, MACC, FAHA, ${ }^{a}$ Thoralf M. Sundt, MD, ${ }^{b}$ Michael A. Acker, MD, ${ }^{c}$ \\ Tirone E. David, MD, ${ }^{\mathrm{d}}$ Robert E. Michler, MD, ${ }^{\mathrm{e}}$ Michael A. Borger, MD,${ }^{\mathrm{f}}$ Gorav Ailawadi, MD, ${ }^{\mathrm{g}}$ \\ Vinod H. Thourani, MD, ${ }^{\mathrm{h}}$ A. Marc Gillinov, MD, ${ }^{\mathrm{i}}$ Ralph J. Damiano, MD, ${ }^{\mathrm{j}}$ Michael J. Mack, MD, ${ }^{k}$ \\ Richard Lee, MD, ${ }^{1}$ Eric A. Rose, MD, ${ }^{\mathrm{m}}$ Timothy J. Gardner, MD, ${ }^{\mathrm{n}}$ Marissa A. Miller, DVM, MPH, ${ }^{\circ}$ \\ Richard D. Weisel, MD, ${ }^{\mathrm{d}}$ and Annetine C. Gelijns, $\mathrm{PhD}^{\mathrm{m}}$
}

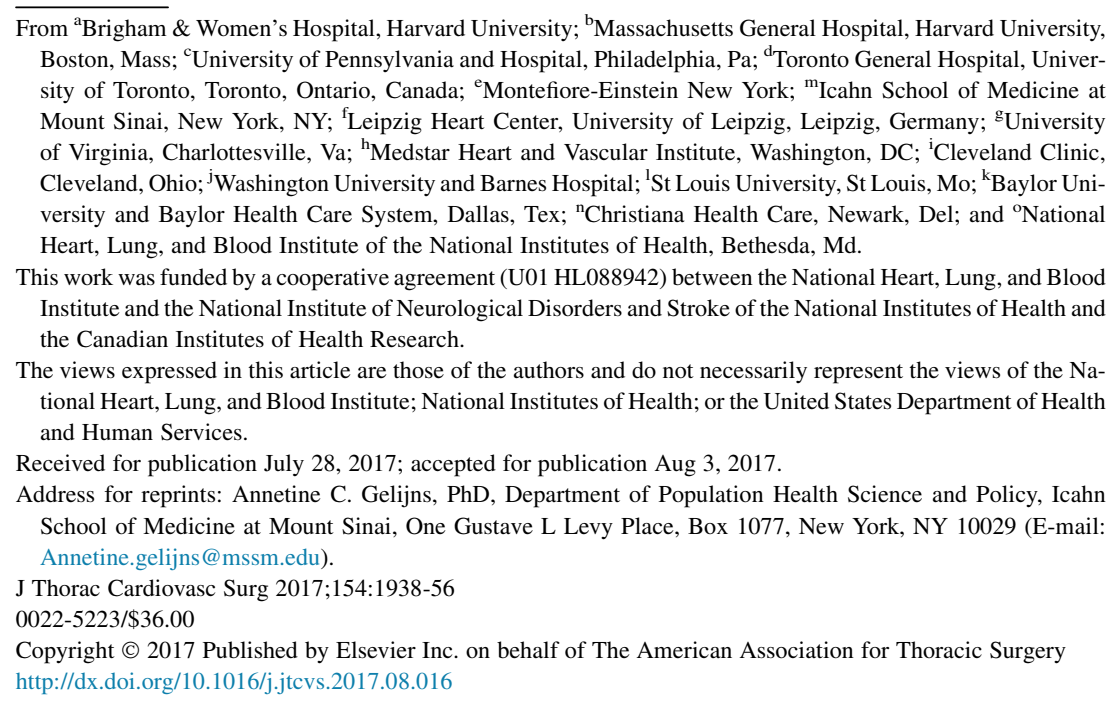

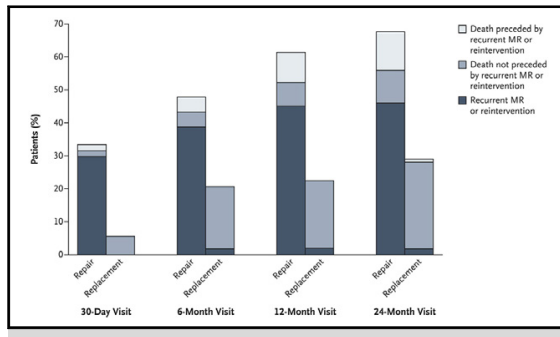

Cumulative failure of mitral valve repair or replacement at 2 years.

\section{Central Message}

The Cardiothoracic Surgical Trials Network provides a collaborative platform to address important questions in the field. Four trials in the New England Journal of Medicine are presented with comments from specialty leaders.

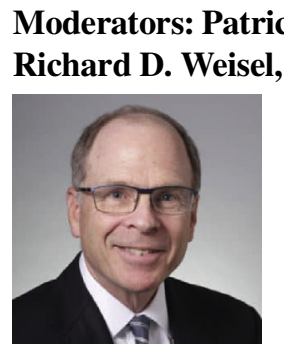

I am joined here on the panel to my immediate right by Dr Vinod Thourani from Emory University and to his right Dr Gorav Ailawadi from the University of Virginia. Dr Richard Weisel, the Chair of CTSN and Editor-in-Chief of the Journal of Thoracic and Cardiovascular Surgery, is the comoderator.

Our first speaker is Dr Annetine Gelijns. Dr Gelijns is the principal investigator at the Data Coordinating Center (DCC) at the Icahn School of Medicine at Mount Sinai in New York.

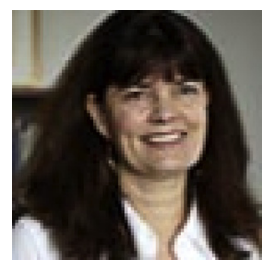

Annetine C. Gelijns, PhD. Thank you, Pat. On behalf of all these CTSN investigators, I would like to thank the leadership of The American Association for Thoracic Surgery (AATS) for organizing this session on the CTSN and its role in growing the evidence base in cardiac surgery.
In introducing the network, it may be valuable to briefly revisit the reasons for its creation. First, cardiac surgery has been a spectacularly innovative and impactful field of medicine. The introduction of major surgical procedures, and incremental change in existing ones, have extended survival and quality of life for many patients. Moreover, patient populations keep evolving. Surgical procedures over time may be extended to lower-risk populations, as has been the case with left ventricular assist devices (LVADs), or they may be applied to older and sicker patients. For example, in 2014 in New York State, close to $50 \%$ of patients undergoing combined coronary artery bypass grafting (CABG) or aortic valve procedures were older than 75 years of age. A rapid pace of innovation requires an infrastructure for rigorous evaluation that provides timely assessments of the value of new treatments as they evolve. Such an infrastructure was lacking, however.

Therefore, in late 2007, the National Institutes of Health (NIH) and the Canadian Institutes of Health Research created the network to conduct trials that address important clinical and population health questions in cardiac surgery. An important objective of the network is to increase the efficiency of clinical research by providing a clinical laboratory in which multiple trials can be conducted without having to create a new infrastructure for each one. To fulfill its mission, the network has addressed challenges in trial 
design and conduct, such as equipoise issues, learning curves, variation in surgeon skill or in medical management of patients, and a high degree of incremental change.

Over time, the network has developed a research agenda that spans a spectrum of translational or early phase trials, quality improvement studies, and comparative effectiveness trials. Our translational research focuses on cardiac regeneration. We conducted a proof-of-concept trial that demonstrated that mesenchymal precursor cells in patients with LVADs were safe and showed a positive efficacy signal in terms of temporary weans from LVAD support. ${ }^{1}$ We are now conducting a follow-up trial with a greater dose of mesenchymal precursor cells, analyzing temporary weans over an extended time period.

Reduction of postoperative infections is a crucial component of quality improvement. In a large prospective cohort study, we found, among others, that particular management practices decreased the risk of infection, such as prophylaxis with second-generation cephalosporins, whereas others, such as stress hyperglycemia, increased risk. ${ }^{2}$

At the heart of the network's research agenda are comparative effectiveness trials, and today we will discuss our severe and moderate ischemic mitral regurgitation (MR) trials. We are conducting 2 additional valve trials in the network. The first evaluates 2 mechanistically different cerebral embolic protection devices in patients undergoing surgical aortic valve replacement. The second is a trial of tricuspid valve repair in patients with either moderate tricuspid regurgitation (TR) or less than moderate TR with annular dilatation undergoing mitral valve surgery for degenerative MR.

Atrial fibrillation (AF) is another target of our comparative effectiveness research, and we will present later the results of our trial assessing the value of surgical ablation for patients with longstanding persistent or persistent AF who underwent mitral valve surgery. Nested within this trial was a randomized comparison of 2 different lesion sets (biatrial maze vs pulmonary vein isolation). We also will discuss the findings of a recent trial comparing the therapeutic strategies of rate versus rhythm control for the management of new-onset postoperative $\mathrm{AF}$.

Interestingly, this trial highlighted the uncertainty surrounding anticoagulation practices and basically set the stage for a new trial evaluating novel anticoagulants versus warfarin for new-onset AF, which is currently in the design phase. So, in conclusion, the network has randomized close to 1750 patients and enrolled some 8000 patients in observational studies. It has generated rigorous science. And the question for today's session is, how do and should these findings affect clinical practice?

Dr O'Gara. Thank you very much, Dr Gelijns, for that review and introduction to the network, and I am sure that all of the principal investigators in the audience would join with me in congratulating you for all of the hard work and leadership over these last several years.

Our next speaker is Dr Thoralf Sundt from Massachusetts General Hospital and the incoming president of AATS, who will opine about the value of randomized controlled trials (RCTs) in cardiac surgery.

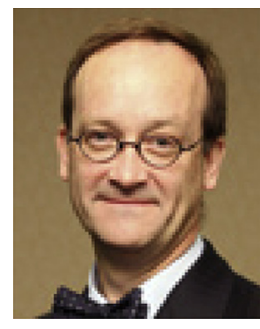

Thoralf M. Sundt, MD. Counter to what you may think, I am not here to take shots at randomized trials and I am not going to try and defend retrospective studies.

I come to praise the CTSN, not to bury it. Prospectively randomized trials are broadly regarded as the highest level of evidence, there is a paucity of RCTs in surgery, and the CTSN has proven that surgeons can conduct randomized trials. That alone is a remarkable achievement.

I accept that randomized trials are a foundation of evidence-based medicine whether we agree with this notion or not. When evidence tables are developed the authors regard data derived from RCTs to be at the top of the pyramid. Those are the facts.

Surgical practice has benefitted from the results of RCTs. We are quite happy with the results of the Coronary Artery Surgery Study (CASS), which demonstrated a benefit to coronary revascularization, for example. ${ }^{3}$ And frankly, randomized trials have kept us out of a bit of trouble. There was a period of time when we thought that bilateral internal thoracic artery ligation was a good idea. A randomized trial disproved that. ${ }^{4}$

Still, it is critically important that we recognize that although randomized trials are powerful, they also have significant pitfalls, and surgeons need to pay particular attention to those pitfalls. RCTs are powerful because they eliminate treatment bias-at least in theory-which is to say bias as to which patient gets which treatment. They also, and very importantly, neutralize the impact of unmeasured covariates provided there are enough subjects-something that propensity analysis cannot accomplish because one cannot account for unmeasured covariates that you don't already have any idea may impact the results.

But there are important pitfalls, and pitfalls that impact surgical trials particularly strongly. I believe it is our responsibility to be aware of these pitfalls and share their importance with our medical colleagues.

First, there is entry bias in any RCT, by virtue of the selection of which patients are or are not entered into the study, which is impacted by the willingness of patients and providers to do so. Second, RCTs require large numbers of individuals to produce meaningful results, but surgical procedures are, in the grand scheme of things, still relatively uncommon. And third, the results of randomized trials can be very sensitive to differences in the treatment itself-an 
issue particularly significant for a surgical procedure as compared with a pharmaceutical.

How do these pitfalls play out in surgical studies? I will present a brief but illustrative cautionary tale.

Imagine a novel procedure is developed and is rapidly adopted by enthusiastic surgical supporters. After a decade of use, some nonsurgeon skeptics suggest a prospectively randomized trial is in order. It is proposed, funded, and initiated.

Over the course of 5 years, 1500 patients are entered in 71 North American, European, and Asian centers at a cost of (only) $\$ 9$ million-you will see why that number is very low in a minute. The results, which are published in the New England Journal of Medicine, show no benefit to surgery as judged by the composite endpoint necessitated by the (relatively) small size of the study. ${ }^{5}$ Does this sound familiar? In the wake of these results, a spirited debate arises in the literature, with surgical proponents arguing the flaws in the study despite their own participation. They raise questions about aspects of randomization, the technical conduct of the operative procedure, and definitions of ineligibility and accordingly generalizability. ${ }^{6}$ Impassioned letters to the editor are written: "I am horrified by the recently published results of the trial, and I know I am not the only surgeon who took part in the trial who feels this way. We know the procedure benefits some patients; if it did not, we would not have performed it as many times as we have."7

On the other side, supporters of the study celebrate the trial as a success for evidence-based medicine and a windfall for health care economics, promising curtailment or elimination of payment for this procedure. Editorialists write: "It is high time the government and third-party underwriters heed the results of this kind of analysis and remove useless procedures from the list of reimbursable medical treatment," ${ }^{8}$ whereas others sing the virtues of randomized trials: "The trouble with randomized trials is that regardless of how many centers they involve is their imperviousness to preconception, hope, and expert opinion."9

The end result was the virtual elimination of this innovative procedure that was, in retrospect, likely very helpful for a select group of patients but was likely overused before the trial. The net effect may have been positive at a population level, with prevention of iatrogenic injury to the larger number of patients unlikely to benefit, but it seems a shame that it is effectively no longer available to the smaller number of patient who likely would benefit.

So, what happened here? This study demonstrates how surgical trials are particularly vulnerable to the 3 pitfalls I alluded to previously. One of them is study size and the problem of small numbers; another is entry bias and the problem of equipoise; the third is the differences in the actual treatment delivered and the problem of technical expertise of the operator as well as modifications of the procedures. All 3 of these aspects set surgical trials apart from the much more familiar and celebrated pharmaceutical RCTs.

Let's start with procedural variation. As surgeons, we all know that procedural success depends on technical factors, including variability in expertise and learning curves. The CTSN has attempted to address that by including among its members only select surgical programs and highly experienced operators. However, pay attention to this factor in randomized trials in general. Learning curves are a real issue, especially if slow enrollment leads to the inclusion of more and more sites each entering a small number of patients. Equally, unlike pharmaceutical products, surgical procedures are subject to modification, seemingly irresistibly so. Again, the CTSN has attempted to control site-to-site variability in technique, but even in this tight-knit group of investigators, it sounds as if this has been a challenge. Both of these issues-technical expertise and procedural variation-impact the actual treatment delivered in ways that may not be familiar to nonproceduralists.

Second is the issue of study size and its relationship to statistical analysis of the result; this is the issue of "power." When the study is complete, outcomes will be examined and a $P$ value calculated by one of a number of statistical methods, some of which are more complex than others. Regardless of how the $P$ value is calculated, it is important to remember that a $P$ value $<.05$ does not mean that 2 outcomes are the same, but it does not mean that there is no difference; it means that there is a less than $5 \%$ chance that the null hypothesis is wrong-which is to say that there is a less than $5 \%$ chance that an apparent difference may be due to chance. That is a subtle but important difference, especially when you talk about small numbers. This is particularly an issue for surgical trials because surgical procedures are, relatively speaking, uncommon. Underpowered studies are at risk of missing an important difference between therapies-be they CABG versus percutaneous coronary intervention or mitral valve repair versus replacement. This is not the case for the pharmaceutical trials or even interventional cardiology trials with which our physician partners are most familiar.

The problem of small numbers is further exacerbated by our third issue- that of entry bias into the study and what Bernard Gersh calls the "gradient of risk" (Bernard J. Gersh, MB, DPhil, ChB, FACC, personal communication, July 1, 2000). In any population, there are a large number of patients who are at low risk compared with a much smaller number at high risk. They are at low risk of the consequences of their disease and oftentimes they are at low risk for the treatment. For example, someone with excellent left ventricular (LV) function and single-vessel disease is at low risk either way. They will probably do fine with no treatment, and you will probably get them through a bypass 
operation without hurting them too much. Pretty much whatever you do, they are going to be fine.

Event rates will be infrequent. The ability to reject the null hypothesis depends critically on study size and event rate.

And who is entered into trials? Those for whom we have equipoise-where we are uncertain and feel they will likely do the same either way. The concept of equipoise was coined by Benjamin Freedman in 1987, referring to genuine uncertainty regarding the benefit of treatment. ${ }^{10}$ That's a concept that is hard for surgeons to wrap their heads around since we are asked every day to confidently make decisions in the face of uncertainty — but is absolutely required for the ethical conduct of a randomized trial. It is generally harder to achieve equipoise when the stakes are higher, although the Placement of Aortic Transcatheter Valve (PARTNER) trial of transcutaneous aortic valve replacement is an example of just the opposite, where patients' risks were so high on both sides that clinicians felt comfortable randomizing. ${ }^{11}$ But if we select out-if we exclude-the patients most likely to benefit because we feel it is wrong to randomize them, the study will show no benefit!

Equipoise is also a problem for patient acceptance as well as the willingness of other clinicians to enroll patients. Both patients and referring doctors want their surgeons confident.

So, what was this case in point to which I referred previously? It was not a cardiothoracic trial at all, but the International Cooperative Study of Extracranial/Intracranial Arterial Anastomosis (EC/IC Bypass) Study. ${ }^{4}$ However, it is easy to find other examples, including lung volume reduction, the Surgical Treatment for Ischemic Heart Failure (STICH) trial, ${ }^{12}$ etc. Again, if you read the editorials in the New England Journal of Medicine after these papers are published, you can almost superimpose the arguments from one study to another. ${ }^{13}$

So, in conclusion: First, RCTs are important; they are important to all of us; we need to do them right. Yes, there are other important sources of information such as registries etc., but the medical community has spoken and payors have listened. Therefore, we must participate. And if we are going to participate, we need to ensure that they are done correctly. We look silly if we complain only after the study is done and we don't like the result. We cannot complain about the results being generalized. They will be. We have to ensure that the right patients are entered and the right procedures are performed. One may complain that only $7 \%$ of eligible patients were randomized into this or that study of percutaneous coronary intervention versus CABG, for example, but the results are going to be generalized.

Third, we need to participate actively and energetically as surgeons. Our medical colleagues and the payers are listening and they are watching. We have got to exercise equipoise or not participate at all. If you are going to participate in the trial but only enter those for whom you think there will be no difference and select out the patients that you really think need the operation, then the result of the trial is going to show no effect of the operation. Quod erat demonstrandum, so, either participate or don't.

And finally, we need to make nonsurgeons aware of these particular aspects of surgical trials. They are fundamentally different from large pharmaceutical trials, particularly with regard to the technical conduct of the procedures.

So, I invite you as we hear these presentations to view these studies through a critical lens: Who was entered? Who was not? What procedures were done? Exactly how were they done? And how big are the numbers and how meaningful are the apparent differences, if any, or the apparent absence of differences.

Thank you.

Dr O'Gara. Thanks very much, Thor.

I would like to now call to the lecterns on either side of the dais Dr Michael Acker from the University of Pennsylvania and Dr Tirone David from the University of Toronto. Dr Acker will begin with a discussion of replacement or repair for severe ischemic MR.

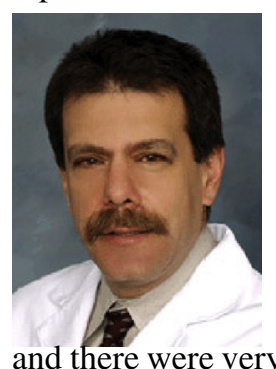

Michael A. Acker, MD. Thanks, Pat. So, one of the first questions the network took on was the question of what to do for severe ischemic MR; was it better to repair or replace the mitral valve? We felt this was a good question to ask, because there was very little information in the literature and there were very few randomized data and very few prospective registry studies to tell us which procedure was most appropriate. Just to operate on severe ischemic MR is somewhat controversial, with the middling suggestion that it is okay with level evidence $\mathrm{C}$ in American Heart Association/American College of Cardiology guidelines, and very little data on the superiority of one versus the other. ${ }^{14}$

As we know, mitral valve repair over the last decade overwhelmingly has used a small annuloplasty ring. This was the procedure that was adopted and has many enthusiasts across the world, not only in this country. However, multiple studies reported an increased rate of recurrence. On the other hand, mitral valve replacement for severe ischemic MR, was accomplished with a high risk of perioperative mortality.

The results of our studies, which have now been followed for 1 and 2 years, are as follows: At 1 year, we saw no difference in reverse remodeling, which was the primary endpoint, no difference in clinical endpoints, such as survival or major adverse cardiac and cerebrovascular events (MACCEs), and no differences in the quality of life. What we saw very clearly was that the small, complete, rigid, significantly undersized annuloplasty ring, with an average size of 28 , was not a reliable operation for eliminating severe MR. At 1 year, a recurrence rate, mostly moderate, was more than $30 \%$ and almost no recurrent MR in the replacement arm. ${ }^{15}$ 


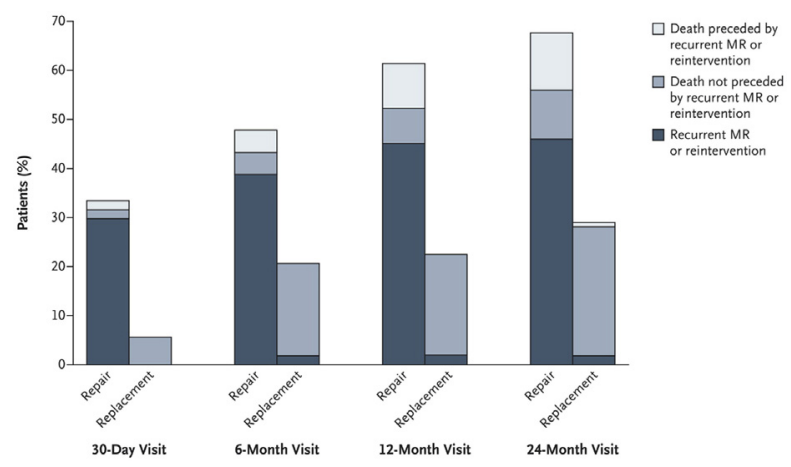

FIGURE 1. Cumulative failure of mitral valve repair or replacement at 2 years. Failure of the intervention was defined as death, moderate or severe MR as seen on transthoracic echocardiography, or mitral reintervention. $M R$, Mitral regurgitation. From Goldstein and colleagues. ${ }^{16}$ Copyright $(C)$ 2016 Massachusetts Medical Society. Reprinted with permission. http:// www.nejm.org/doi/full/10.1056/NEJMoa1512913.

And what was presented recently at American Heart Association meeting last year was the 2-year follow-up. ${ }^{16}$ At 2 years, we found no difference in reverse remodeling, which is the surrogate for the clinical endpoint with either repair or replacement. Both groups did show a significant decrease from baseline- a good thing. We saw that mortality was not statistically different. In fact, mortality was low, extremely low, compared with historical comparisons, less than $5 \%$, but at 30 days the mortality was $1.6 \%$ with repair and $4 \%$ with replacement, and the $P$ value was not significant. At 1 year, $14 \%$ died after repair, $18 \%$ after replacement, and the difference was not significant. At 2 years the survival curves were almost superimposable and plateauing between the 2 groups. No difference. MACCE was almost identical with no difference between repair or replacement.

We saw the continued problem with the small annuloplasty ring as the sole operation and that there was now at 2 years almost a $60 \%$ recurrence rate of primarily moderate $\mathrm{MR}$, and again, the replacement valves were holding up at 2 years with almost no recurrence (Figure 1). ${ }^{16}$

And if you look at the outcomes over time combining death with or without recurrent MR, there was a difference between groups. Repair may not be the best operation for everyone, using a broad brush, if you just put in a small annuloplasty ring; at 2 years you will have nearly two-thirds of your patients either dead or have moderate MR compared with replacement, where the death rate is very similar but very few have recurrent moderate MR.

So, does it matter? At 1 year we saw no clinical hit as a result of the recurrent MR. Importantly, we did see something interesting. For the one-third of patients who did not have recurrence, we saw significant better reverse remodeling compared with the group that was repaired and had recurrence. And interestingly, although not directly statistically compared, the patients who underwent replacement also were not nearly as good, despite the absence of MR, to the group with the ring that had no recurrence.

At 1 year we started to see, I think, the effects of this recurrent MR in the repair group. We started to see that the patients with recurrent heart failure at 2 years was greater in the repair group compared with the replacement; no other adverse events were different.

Importantly, really importantly, the hospitalizations, if you repair all-comers, readmissions or CV readmissions were greater for heart failure and for use of pacemakers in the repair group compared to replacement. At 2 years we are seeing a clinical hit of the recurrent MR. And we saw a strong trend, using the tool Minnesota Living with Heart Failure, that those that had repair did not feel as well as those that had replacement at 2 years.

This is a limited study, and Thor went over why randomized studies are inherently limited. The primary endpoint is an echocardiographic one, not a clinical one. To do a study with a clinical endpoint would have required a larger number of patients than we could have logistically randomized.

The follow-up is still limited. We hope to follow these patients for 5 years. And importantly, it did not address the emerging field of subvalvular procedures for severe ischemic MR.

I remind you, this is a very limited procedure done by a few great surgeons that has not achieved proven applicability across our field.

In conclusion, there is no difference in the degree of $\mathrm{LV}$ remodeling at 2 years or in survival. There is now a divergent clinical outcome not seen at 1 year but now evident at 2 years. The repair group has a greater rate of recurrent MR and was more likely to have heart failure, adverse events, cardiovascular readmissions, and a strong trend to a worse quality of life.

Importantly, mitral valve replacement for ischemic severe MR has been proven with total chordal sparing to be a safe and acceptable option in patients with severe ischemic MR and is supported by level of evidence A. It is okay to replace the valve.

Finally, and importantly, the greatest remodeling was seen in the repair patients without recurrence. We need to figure out who is going to recur so we can model our procedures best to the patient. Replacement certainly confers the most durable correction, and I hope that we will be able to follow these patients for 5 years to determine the impact of the prosthesis vis-a-vis the durability of the MR correction.

Dr O'Gara. Thanks very much.

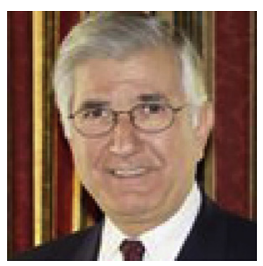

Tirone E. David, MD. I find myself in an impossible position to discuss this paper, because after Thor Sundt and this data from Michael Acker, we all should go home and begin to replace mitral valves for ischemic MR. 
But let me be the devil's advocate and remind you of the anatomy of the mitral valve and the effect of ischemia on it. There is no worse subject in surgery than to try to randomize a disease with a spectrum as large as this, even larger than mitral valve prolapse, which is complicated even in trying to develop some guidelines to guide surgeons and cardiologists when to repair and when to replace.

This process starts with an infarct and the myocardial cells die and then fibrosis takes over and remodeling begins, if the patient survives. Ninety-five percent of patients who have an inferior wall infarct never develop MR; 5\% do. I discovered this in 1998 when I stopped to think, why do I have so much recurrence of MR after mitral valve repair? Well, I tell you what I have learned.

You might have an impaired ventricular function but intact mitral valve, and yet approximately $5 \%$ of human beings who thrombose their right coronary artery and infarcted the inferior wall develop MR. Why only 5\%? Why not $100 \%$ ?

I will tell you why. Anatomy. The anatomy of the papillary muscle and the posterior wall that anchors the medial half of the mitral valve varies among us. Let's go back to the pathology lab and study autopsies again.

Take a look at the papillary muscle of a patient who died of MR 3 or 4 years after infarction. The inferior wall has a scar tissue in it, and the papillary muscle is fibrotic. More importantly, there is in the mitral valve something called the mid-mitral line that we surgeons don't pay enough attention to. The mitral valve has an anchoring mechanism on the lateral half, but on the medial half it is very different. In myxomatous mitral valves, the prolapse almost entirely happens on the medial half of the mitral valve and for ischemic MR the prolapse also occurs on the medial half of the mitral valve. Very seldom is the lateral half affected; very seldom the lateral half has prolapse. Why? Anatomy again. The posterior leaflet on the medial half is not anchored by the papillary muscle alone but the valve has trabeculae everywhere from the insertion of the annulus down to the free margin.

Another patient who died from a car accident would have had ischemic MR if he suffered a posterior wall infarct. The anatomy is different. The anterior leaflet geometry also is affected in this same patient. Where is the strut chordae on the posterior papillary muscle? There is none to be severed. Everything is on the free margin. To develop ischemic MR, you have to have chordae tendineae that goes all in the rough area, in the coaptation area, to drag the anterior leaflet into the ventricle. Otherwise, there is no ischemic MR. And very simplistically, Robert Levine and I talked about this and he introduced the concept of severing those chordae and doing a small annuloplasty, and we forgot about the rest of the mitral valve, which was another mistake.

As early as 1995, we introduced this type of annuloplasty, an asymmetric annuloplasty. It has to be a rigid ring. You have to sever the chordae tendineae, and then you have to have at least twice more length anteriorly. And that is the key to correct ischemic MR. In $100 \%$ of cases? No. You still have to be selective.

If the posterior wall is dyskinetic, mitral valve replacement is a better operation. If the gap is too big, it is impossible to bring those leaflets together. And finally, if the tenting is more than $10 \mathrm{~mm}$ or the posterior leaflet angle is more than 45 degrees, unless it is a huge leaflet, you can't bring it together either.

So, it is a complex mitral valve repair and may be as complex if not more complex than a floppy valve repair. I think we have to individualize the case according to the pathology, and frequently you don't have the tools to identify all this preoperatively. In that case, replace.

Another mistake if you replace is to insert a valve as big as the annulus, then you are going to have a hypokinetic posterior wall. It should be a small mitral valve in ischemic MR. If you use a tissue valve, use one that is hemodynamically very effective, because the patient is not going to outlive the valve anyhow.

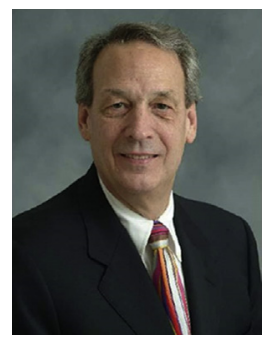

Dr Weisel. The next presentation will be Robert Michler from MontefioreEinstein, who will discuss surgical repair of moderate ischemic MR. ${ }^{12}$

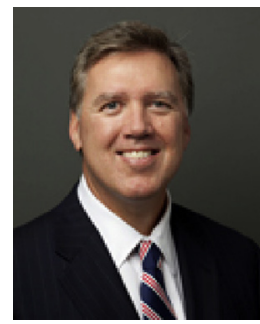

Robert E. Michler, MD. Distinguished panel and guests. I am delighted to be able to share some perspectives on moderate ischemic MR as we have learned from the CTSN sponsored by the National Heart, Lung, and Blood Institute (NHLBI).

We all know that coronary ischemia and myocardial infarction can produce MR as a result of several factors, including the dilatation of the ventricle, myocardial scar formation, wall motion abnormalities, and, in extreme cases, separation of the papillary muscles.

The treatment for this lesion has several surgical options, and there are differences of opinion with respect to how to manage this condition. These options include bypass surgery alone or the addition of a restrictive annuloplasty to bypass surgery.

The CTSN recently published in the New England Journal of Medicine and presented this year at the American College of Cardiology meeting the 2-year results of randomized trial for the management of 301 patients with moderate ischemic MR. ${ }^{17}$ The choices of therapy were bypass alone or bypass with the addition of a restrictive annuloplasty. 


\section{MR Persistence ( $\geq$ moderate)}

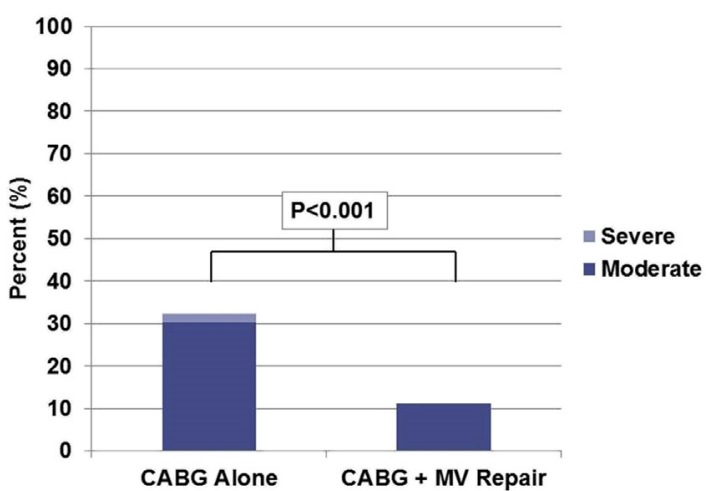

FIGURE 2. Persistent more than moderate $M R$ was greater after $C A B G$ alone than after $\mathrm{CABG}$ and MV repair. Presented at the American College of Cardiology Featured Clinical Research, April 3, 2016. MR, Mitral regurgitation; $C A B G$, coronary artery bypass grafting; $M V$, mitral valve. From Michler and colleagues. ${ }^{17}$

The primary endpoint was the change in left ventricular end-systolic volume index (LVESVI). At baseline, there was no significant difference between the 2 groups, and at 2 years there was, similarly, no significant difference between the groups, although both groups did improve in terms of LV reverse remodeling as measured by LVESVI. Of note, there was a 3 -fold increase at 2 years in the persistence of moderate or severe MR in patients receiving bypass surgery alone (Figure 2). ${ }^{17}$

In those patients who received a restrictive mitral annuloplasty there was no progression to severe MR, and in the bypass alone group only a small percentage of patients progressed to severe MR.

Mortality was not different between the 2 groups at 1 year or at 2 years. ${ }^{17,18}$ At 2 years, serious adverse events and rehospitalizations were not significantly different between the 2 groups. The perioperative event rate of neurologic events (seizure disorders, metabolic encephalopathy, and stroke) were greater in those receiving a mitral procedure. Similarly, supraventricular arrhythmias were more frequent in those receiving a restrictive annuloplasty.

In the 2-year analysis, we examined wall motion in a 17segment model or bullseye model of the heart. Specifically, we looked for changed in global LV function as well as regional function in the posterolateral inferior walls, which are the areas subtended by the papillary muscles. In all patients at baseline, there were significant wall motion abnormalities and in particular, abnormalities in the posterior-inferior-lateral walls. If we examine those patients who had no persistent or recurrent MR at 2 years, there was a significant improvement in their wall motion, which did not occur in the population of patients who had persistent or recurrent MR, irrespective of the operation the patient received.

In summary, the 2-year Moderate Mitral Regurgitation CTSN trial demonstrated no difference between treatment groups in the endpoints of LVESVI, New York Heart Association (NYHA) Class, MACCE, ejection fraction, and survival. There was a 3-fold improvement in MR grade with the addition of a restrictive mitral annuloplasty. Moreover, patients in both treatment groups in whom MR grade improved or disappeared also manifested a marked improvement in left ventricular wall motion.

Why are the CTSN trial results different from 2 previously published randomized studies of patients with moderate MR? Fattouch and colleagues, in a trial of 102 patients, showed an improvement in LVESVI, EF, MR grade, and NYHA class, with no difference in survival. ${ }^{19}$ Chan and colleagues, in 73 patients in the Randomized Ischemic Mitral Evaluation (RIME) trial, showed an improvement in LVESVI, EF, MR grade, NYHA class, peak oxygen uptake, and brain natriuretic peptide, with no difference in survival. ${ }^{20}$

Are there elements of these studies that can explain the differences in outcomes seen between these 3 randomized clinical trials? I have examined the data carefully in these trials. One of my first observations is that the patients in the Fattouch trial had a baseline mean end-diastolic dimension that was $5 \mathrm{~mm}$ larger than the patients in the CTSN trial. Moreover, the patients in the RIME trial had a baseline mean LVESVI that was $20 \mathrm{~mL} / \mathrm{m}^{2}$ larger than the patients in the CTSN trial. Therefore, patients in the Fattouch and RIME trials had significantly larger ventricles at baseline than those patients in the CTSN trial.

Furthermore, in patients receiving a restrictive mitral annuloplasty, the mean end-diastolic dimension decreased by $7 \mathrm{~mm}$ in the Fattouch trial, and the mean LVESVI decreased by $22 \mathrm{~mL} / \mathrm{m}^{2}$ in the RIME trial, compared with $2 \mathrm{~mm}$ and $9 \mathrm{~mL} / \mathrm{m}^{2}$, respectively, in the CTSN trial. Therefore, patients in the Fattouch and RIME trials had larger ventricles at baseline and those who received a restrictive mitral annuloplasty had more than twice the reduction in LV dimension than was seen in the CTSN trial.

With these data in mind, which patients with moderate ischemic MR should receive bypass surgery alone? In my opinion, such patients would include CTSN-like patients: patients with similar baseline demographic and operative characteristics; patients with mildly reduced ejection fraction; nonseverely dilated ventricles; and evidence of reversible ischemia. The rationale for this recommendation is that in the CTSN population the relief of moderate MR occurred in $70 \%$ of the patients, progression to severe MR was uncommon and moderate MR was clinically well tolerated.

On the other hand, which patients should have a restrictive mitral annuloplasty in addition to bypass surgery for moderate ischemic MR? These patients would include 
those with a poor bypass target to the posterior descending coronary artery or circumflex coronary artery; those with posterior-inferior-lateral scar or a basal aneurysm or dyskinesia; a large left ventricle with an end-diastolic dimension of greater than $55 \mathrm{~mm}$ or LVESVI of greater than $70 \mathrm{~mL} / \mathrm{m}^{2}$. In these patients with very large ventricles, one should consider a papillary muscle plication. Lastly, patients with severe LV dysfunction because of the uncertainty of whether an improvement in LV function and papillary muscle function will produce a lasting reduction in MR.

Although these data help our understanding of how best to manage patients with moderate ischemic MR, they do not produce the fidelity we need in predicting which patients will have a lasting benefit from bypass alone nor which patients will need more than a restrictive annuloplasty to achieve a durable repair.

Thank you very much for your attention.

Dr Weisel. Our discussant is Michael Borger from Columbia University.

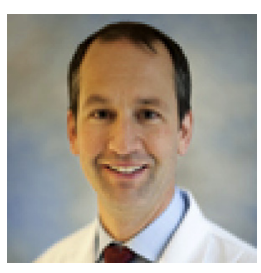

Michael A. Borger, MD. Thank you, Richard, and I just want to extend my congratulations to Pat and the rest of the CTSN leadership to show that randomized trials can actually be doneand done well-in cardiac surgery. I do not have any disclosures which are relevant to this talk.

I would just like to start by saying that I agree with everything that Dr Michler said. A couple of minor differences of opinion, however, will be discussed. What I also want to say is that I didn't want to present a lot of data, but the numbers that I will quote are well supported by methodologically sound papers from the literature. Finally, I want to reiterate that we are discussing patients with moderate functional MR who require coronary revascularization, not severe functional MR or organic MR, which are entirely different situations.

We have known for 20 years now-since the Survival and Ventricular Enlargement (SAVE) trial results were published $^{21}$ - that mild or more MR has a markedly negative impact on long-term survival postmyocardial infarction. However, this observation alone does not give us carte blanche as cardiac surgeons to say that we should be correcting all functional MR in patients with coronary artery disease. We don't know how much of the observed decreased survival is due to the MR and how much of it is due to the fact that patients with a more extensive myocardial infarction are more likely to have MR.

The other thing that we need to remember is that no study, neither retrospective analyses nor a prospective randomized trial, have shown a benefit on long-term survival for mitral valve annuloplasty for functional MR. And we also need to acknowledge that mitral valve annuloplasty is associated with its own perioperative risks. One needs to ensure that the patient can survive the operation before focusing too much on possible long-term benefits of surgery.

So, the question becomes, what are the potential complications and risks of adding a mitral annuloplasty procedure to a coronary bypass operation? Well, one negative consequence is the significantly increased aortic crossclamp and cardiopulmonary bypass (CPB) times. In this study, there is an average increase of 50 minutes of myocardial ischemia and 60 minutes of $\mathrm{CPB}$ time, not insignificant amounts.

Do those increased times have clinical effects? The answer is "definitely," at least in certain patient subgroups-for example, patients who present with acute coronary syndrome and are treated with dual-antiplatelet therapy. They are going to have an increased risk of bleeding if you add another 60 minutes of CPB.

Another group of patients in whom increased CPB times would be clinically relevant would be those with preexisting kidney disease. So, if a patient has a creatinine of more than $1.5 \mathrm{mg} / \mathrm{dL}$, you may want to think twice about doing a mitral annuloplasty procedure.

Also, those patients with preoperative respiratory insufficiency. A forced expiratory volume in 1 second of less than $1.2 \mathrm{~L}$ or less than $50 \%$ of predicted should make the surgeon reconsider adding mitral valve repair to the coronary bypass operation because of the increased risk of prolonged ventilation.

As was demonstrated in the previous presentation, cerebrovascular complications were greater in the CTSN randomized trial in patients undergoing mitral valve repair. ${ }^{17}$ One should consider avoiding an annuloplasty in patients who have known risk factors for cerebrovascular complications.

What are the other risks associated with mitral annuloplasty? There is about a $10 \%$ increase in AF compared with coronary bypass surgery alone; Dr Michler already showed that. For pacemakers, it is about a $2 \%$ increase. There are also rare but catastrophic injuries to the circumflex artery or to the aortic valve.

Some patients in whom the surgeon intends to repair the mitral valve may also end up with a mitral valve replacement. This is the only statistic that I couldn't really find in the literature. For moderate MR, how many of those end up getting a replacement rather than just an annuloplasty? I don't know what the rate is, but it did not occur in any patient in the randomized trials. It occurs in probably less than $1 \%$ of patients.

And then there is the increased risk of stroke as well, an occasionally devastating outcome. There is an increased risk of stroke of $1 \%$ to $2 \%$ compared with isolated coronary bypass surgery when a mitral annuloplasty is performed, and not all of these strokes occur in patients with known cerebrovascular risk factors. 
What about the late risks of adding a mitral annuloplasty? There is an increased risk of bleeding, at least in the first 3 months postoperatively when the patient is on Coumadin. There is also a risk of stroke or transient ischemic attack that is slightly increased from the randomized trials, about $1 \%$ in the first year, but then thereafter it seems to level out.

Functional mitral stenosis after an undersized annuloplasty is a poorly described and poorly understood clinical phenomenon. I am guessing its occurrence rate is around $5 \%$. But it may be greater, and certainly the smaller the ring is the greater the risk of this complication.

The risk of endocarditis after mitral valve repair, looking at Dr David's paper in Circulation, is very uncommon, occurring in only $1 \%$ of patients at 10 years postoperatively. $^{22}$

Another possible long-term complication is mitral reintervention, either mitral valve surgery or percutaneous mitral intervention. Mitral valve reintervention rates are the same after isolated coronary bypass surgery versus mitral valve annuloplasty in patients with moderate MR. There is no difference between the 2 approaches.

And finally, survival. As I already said, there is no difference in long-term survival between these two operative strategies. You cannot use survival to justify adding a mitral annuloplasty to $\mathrm{CABG}$ in a patient with moderate functional MR.

So, what are the potential benefits of concomitant mitral valve surgery? Well, one of the biggest benefits is that the rate of moderate or more MR during follow-up is definitely less: $11 \%$ versus $32 \%$ at 2 years for the CTSN trial; $4 \%$ versus $40 \%$ for RIME; and $0 \%$ versus $60 \%$ for the Fattouch randomized trial. The possible reason for the increased benefit in the latter 2 trials has already been mentioned, that is, that patients in these trials had larger left ventricles preoperatively.

There is also some improved LV reverse remodeling postmitral annuloplasty, as you saw from Dr Acker's presentation, but only if there is no recurrent MR. And there are some studies, not just the 2 positive trials, showing improved NYHA class, post-mitral annuloplasty for moderate MR. Even in the negative CTSN trial, the investigators observed statistically improved quality of life during 2-year follow-up in one of the quality of life tests performed.

I would like to sum up by saying that the decision of whether or not to perform a concomitant mitral annuloplasty should be patient-specific. If the patient is younger and therefore has a longer life expectancy, I am more likely to do a mitral annuloplasty. However, young age doesn't always equate with longer life expectancy. I always ask my patients how old their parents were when they died, and if the patient has already outlived their parents by 10 years and they have comorbidities, they are probably not going to live very long.
Another variable I consider is whether or not the mitral valve appears repairable. Less severe tethering, for example, I would tend more toward performing a contaminant annuloplasty.

If the patient has a very bad LV ejection fraction-and here I disagree with Dr Michler-if they have an LV ejection fraction less than $25 \%$, then concomitant mitral repair may be enough to tip them toward a negative outcome. One needs to think more about 20-hour survival than 20-year results in such patients.

Then there is the issue of reversibility that has already been alluded to. If there is a lot of reversible myocardium in the inferolateral wall, probably coronary bypass surgery alone will take care of the moderate MR.

Finally, other issues to consider are the number of comorbidities and the effects of increased CPB time on such patients, the number of planned bypass grafts, and the general conduct of the operation. One word of advice is: Do not box yourself in at the beginning of the operation and say to yourself that you must to do a mitral annuloplasty. If you have troubles with your distal coronary targets-if you can't find the left anterior descending coronary artery because it is intramyocardial, for example - and it is turning into a long operation, maybe you should just bail out on the mitral annuloplasty.

These are all difficult decisions, but I hope that with the help of some of the figures I've quoted from the literature, I have been able to enlighten this topic a little bit.

Thank you very much.

Dr O'Gara. Thank you very much, Michael. And now I would like to call on our panelists for a brief discussion of ischemic MR. So, for Gorav and Vinod, 3 questions. You can answer 1 or all 3 if you'd like.

One would be, could you share with us some of the obstacles you faced as a principal investigator randomizing your patients in a trial of ischemic MR?

Second, what do you think the impact of these trials has been on your practice or your institution's practice in the short term?

And then third, where are we going with transcatheter techniques for ischemic MR and will this evolution change the paradigm further in the short term?

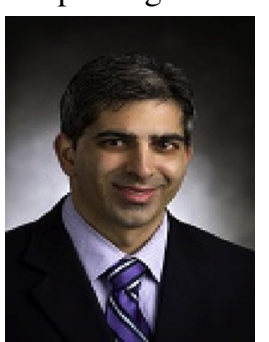

Gorav Ailawadi, MD. I will be happy to take those questions first. The first question relates to equipoise, and at our institution, we have strong leadership and collaboration that encouraged us to get heavily involved in these various trials. Without question, there were insufficient data on either side for both of these trials that we could not convincingly say that one approach was better than the other. This belief took a little convincing of all of our faculty members as many had been used to practicing in a particular manner. 
Nevertheless, we had strong enrollment by the entire network due to the fact that these were highly relevant questions that were being asked with these particular two trials.

Regarding clinical practice and how these trials have affected our approach now-in the past there has been a strong bias for repair at our institution for severe ischemic MR, which has changed to a predilection for replacement, particularly in patients with a basal aneurysm. We also don't feel forced to repair the mitral valve in the majority of patients with moderate MR undergoing CABG but only in select patients, which was highlighted by the speakers.

And finally, the impact with transcatheter technologies, as I mentioned, we have to be careful about the patient population that you are talking about and not be too aggressive about extrapolating. It is interesting that the conclusions made by our severe ischemic trial are being extrapolated for all functional MR. Not all functional MR is the same. There are differences in LV geometry and tethering between ischemic and nonischemic functional MR, and the 2 groups should not be lumped together when thinking about transcatheter valve replacement versus repair. Certainly, there is much enthusiasm from a number of us involved with transcatheter technologies, and further trials will clarify the role of each.

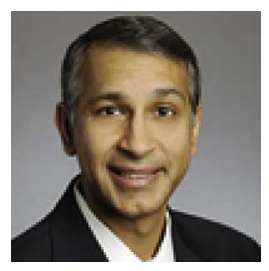

Vinod H. Thourani, MD. I just want to add 1 or 2 things to the discussion by Gorav. The second question that has come up has been the volume of cases in mitral valve repair versus replacement in the United States. I do think that there has been a shift. When I talk to other surgeons at both the national meetings like the Society of Thoracic Surgery (STS) and the AATS meetings and regional meetings, they note that there is less pressure from the cardiologists in these high-risk patients with severe ischemic MR about performing a mitral valve repair. I do think it may be conceivable that some surgeons were doing potentially bad repairs, just to say that they did the repair. I think that becomes potentially dangerous. Also, I think that we as a surgical community need to look harder to improve adjunctive therapies in addition to just implanting an undersized ring in this patient population. Where does papillary plication or re-approximation play a role?

On the subject of moderate concomitant MR, what I continue to do is to perform a preoperative magnetic resonance imaging (MRI) to help guide me on when to operate on the mitral valve. If we have an MRI that shows a very viable myocardium, specifically in the interior wall, and it doesn't show the papillary muscle or left ventricle to be to enlarged and a normal left atrial size, I am more likely to potentially just perform a coronary bypass in those patients and not repair mitral valve. In those that are severe, that have a MRI that shows nonviable inferior wall, I am more likely to replace those patients and not perform a repair.

So, most importantly, I think these studies have allowed the surgeons to feel more comfortable about having a robust conversation with their cardiologists about the benefits of repair or replacement with chordal sparing.

With regard to new technologies, I think results from studies like the Cardiovascular Outcomes Assessment of the MitraClip Percutaneous Therapy for Heart Failure Patients with Functional Mitral Regurgitation (COAPT) trial are going to give us a good idea where this therapy fits into the world of functional MR. ${ }^{23}$ Overall, I think that multiple adjunct techniques are going to work. As some in this audience already know, MitraClip is used quite commonly in functional MR in Europe, but not so much in the United States. So, the horizon is wide open for these, especially with new transcatheter technologies including a transseptal mitral valve ring and the host of transcatheter mitral valve replacement valves.

Dr Borger. Can I just make one comment about that? There is no doubt about it that the trials that were presented today have had an effect on the way people are starting to think. If you just look at the prices that were recently paid for of the companies with transcatheter mitral valve replacement devices, you realize the CTSN trials had a huge impact on the amount of money that is being invested in the area. Whether that is right or wrong, time will tell.

Dr Thourani. Annetine and I and others are in the process of looking at the STS database before and after the trials to see if the trials have made a difference in the realworld practice. I think that will be important.

Dr O'Gara. So, our last question is for Dr David. Having heard these presentations, what advice would you give us with regard to future investigations in ischemic MR?

Dr David. I said before, my fear is that ischemic MR is going to be treated with mitral valve replacement from now on, and I think that is wrong. We have to define which patients can have repair. In those patients, I have no doubt in my mind that they will benefit in the long term with repair as opposed to replacement. And some patients have such advanced cardiac disease that repair is not going to help them.

Dr O'Gara. We certainly hope that with the more than 550 patients randomized into these two trials we will have some additional information to try to predict who will respond to repair.

Thank you very much.

Dr Weisel. The next subject is the surgical treatment of AF. The first presenter will be Marc Gillinov from the Cleveland Clinic, entitled "Surgical ablation of atrial fibrillation during mitral-valve surgery." 24 


\section{All Patients}

A

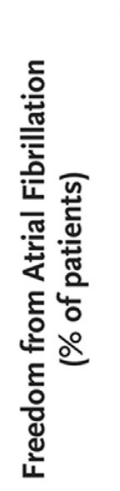

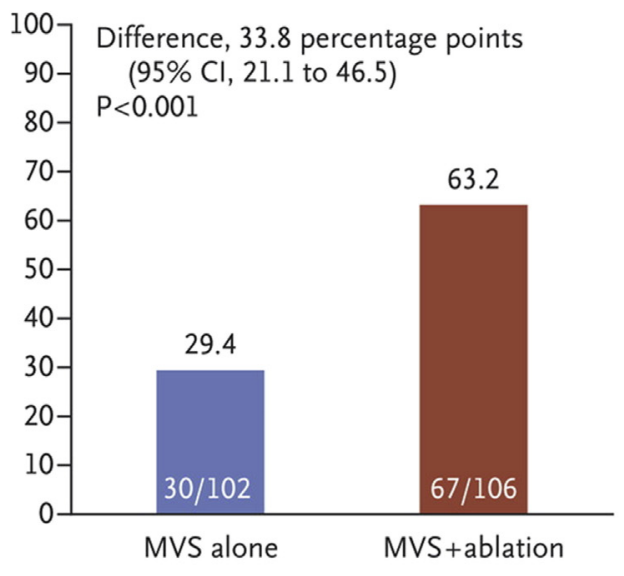

Ablation Group

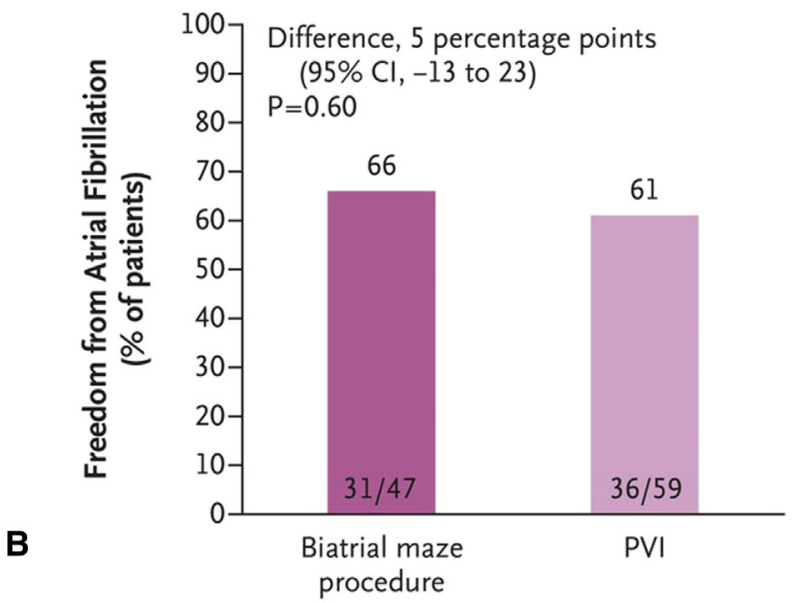

FIGURE 3. Freedom from atrial fibrillation after MVS. Freedom from atrial fibrillation was defined as the absence of the condition at both 6 months and 12 months, as assessed by means of 3-day Holter monitoring. A, Freedom from atrial fibrillation after MVS for all patients with 6-and 12-month Holter data. B, Freedom from atrial fibrillation after MVS for the 106 patients in the MVS + ablation arm. CI, Confidence interval; MVS, mitral valve surgery; PVI, pulmonary vein isolation. From Gillinov and colleagues. ${ }^{24}$ Copyright @ 2015 Massachusetts Medical Society. Reprinted with permission. http://www. nejm.org/doi/full/10.1056/NEJMoa1500528.

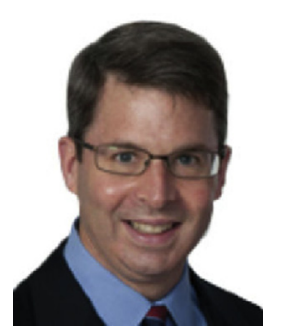

A. Marc Gillinov, MD. I am going to talk about surgical ablation of AF. The reason to do this trial is that in the United States today, only about one half of patients who come to the operating room with pre-existing $\mathrm{AF}$ have an ablation. The other half of the time the AF is left untreated.

Number one is a concern about safety, and number 2 is a concern about effectiveness.

There is plenty of literature concerning surgical ablation and the maze procedure but very little randomized controlled data. This trial focuses on those with mitral valve disease and pre-existing AF, because the mitral valve patient is the one who is most likely to have AF, and also because, as Ralph Damiano has said, if you are doing a mitral valve operation in a patient with $\mathrm{AF}$, you have a once in a lifetime opportunity to treat the AF because you are inside the left atrium.

This paper, like all the rest of the CTSN studies, resulted in a high impact publication that has influenced practice. ${ }^{24}$ The purpose, again, was to assess both safety and effectiveness of surgical ablation in the mitral valve patient.

In addition, we sought to compare 2 different lesion sets for ablation, pulmonary vein isolation and a classic biatrial maze procedure. I want to make clear that we did not get an answer to the question which one of these lesion sets is most effective; the trial was not powered to answer that question through its primary endpoint.

The definitions for AF change over time, so I wanted to include the definitions we used, which were the definitions in place according to the Heart Rhythm Society consensus statement for persistent $\mathrm{AF}$ and long-standing persistent AF. Perhaps the key point here is that this is not paroxsymal AF. We did not look at paroxsymal AF.

The patients received 1 of 2 therapies. Half had no ablation but did have treatment of the left atrial appendage. The other half had ablation, and among those with ablation, half had pulmonary vein isolation plus treatment of the appendage and half had a biatrial maze. So, all received treatment of the left atrial appendage.

The primary endpoint is a little different from primary endpoints in many other studies, as it was specified by the Food and Drug Administration (FDA). It was freedom from AF at both 6 and 12 months by 3-day Holter monitor. That means if you had AF at 6 months but at 12 months you were in normal sinus rhythm, you were still considered a failure. The trial was powered to detect a $20 \%$ difference between ablation and no ablation, and, appropriately, anyone who died was counted as a failure even if that person had had no AF.

We screened 3500 patients to identify 260 eligible patients with AF. That doesn't mean we had 3500 patients with AF. We screened all-comers in cardiac surgery, identified those with A-fib, sought to randomize them either to valve surgery alone or valve surgery plus ablation, and we imputed data on about $20 \%$ who didn't have complete follow-up. For this trial, we had very good follow-up.

As Dr Sundt pointed out, any trial applies only to those who are enrolled, even though the reader tends to generalize the results. But, just to be clear, here's who we enrolled: older patients, mean age about 69 years; long-standing persistent AF was most prevalent; and most patients had organic MR. 
Ablation added about 15 minutes to bypass time. So, it does not prolong the operation much. The primary endpoint, freedom from AF at both 6 and 12 months was $63 \%$ if you had ablation versus $29 \%$ if you had valve surgery alone (Figure 3). ${ }^{24}$ Others might say, "I get $98 \%$ success in my practice.' That's good. Actually, that's great. But the point here isn't the specific number but the fact that ablation is more successful at controlling rhythm than is no ablation.

And here is information that is more often misinterpreted than correctly interpreted. The freedom from AF was similar between those who had a biatrial maze compared with those who had pulmonary vein isolation. The study was not powered to detect a difference between these lesion sets based on the primary endpoint of Holter monitoring. However, it does suggest that if there is a difference it may not be as large as many believe.

Doing ablation did not increase mortality nor MACCE. However, performing an ablation did increase the likelihood of having a pacemaker by a factor of 2.6. This result is an outlier, and we are examining the risk factors for pacemaker implantation in this study.

In summary, ablation is successful at controlling heart rhythm and is more successful than is doing mitral valve surgery alone. We saw no apparent difference between pulmonary vein isolation and biatrial maze lesion sets in our primary endpoint involving Holter monitoring. Ablation did not have a mortality cost or a cost in terms of MACCEs, but in this series ablation was associated with more pacemakers.

Thank you.

Dr Weisel. The discussant for this paper will be Ralph Damiano from Washington University in St Louis.

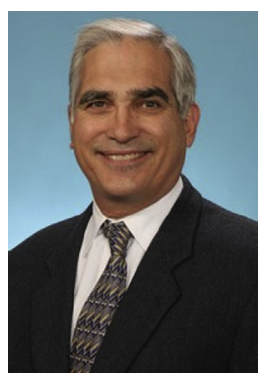

Ralph J. Damiano, MD. Thanks, and I would like to also congratulate Marc and the CTSN investigators on performing a very excellent and I think well needed multicenter randomized trial looking at surgical ablation of AF. I would like to discuss that. I think it is important.

This was the largest randomized trial, not the first, but certainly the largest to look at the efficacy and safety of surgical ablation in patients undergoing mitral valve surgery, which everyone knows is the most common indication for surgical ablation of AF in the world today.

And, as Marc showed, the big take-home point from this trial, which is I think really important for everyone's practice, is that doing an ablation at the time of mitral valve surgery restores sinus rhythm in a much greater percent of patients than not doing an ablation and did not increase the risk of the procedure in any appreciable manner.

I think the only issue that many people have had with the trial, and it goes back to what Dr Sundt said about the generalizability of these results, is the data that Dr Gillinov presented showing no difference between a biatrial maze and pulmonary vein isolation. And although the study clearly and very well mentioned in the manuscript wasn't powered to look at this problem, having this type of figure in the manuscript certainly led and has led many people to jump to the conclusion that there is no difference.

And I would just like to point out some of the drawbacks of making that beside the fact that that wasn't really the point of this trial. Like I said, they acknowledged that it wasn't powered, and remember how few patients actually were randomized in the trial. In the biatrial maze group, less than 50 patients were available for late follow-up, and these came from a significant number of centers. The actual number of patients that each center put in was actually quite small.

Moreover, I would have to say that the way the results are reported are unusual, as Dr Gillinov said, and they don't follow the recommendations of what have been 2 consensus statements that have been endorsed by the cardiology societies and all the surgical societies on AF ablation, and this was the last one, in 2012. But failure is supposed to be defined as any episodes of AF or atrial flutter or atrial tachycardia lasting more than 30 seconds after a 3-month blanking period. We should define success as freedom from both arrhythmias and anti-arrhythmic drugs at 12 months. And if you then looked at the trial definition, it was just freedom from $\mathrm{AF}$ at 6 and 12 months, as Dr Gillinov said.

If you then read the manuscript, approximately $13 \%$ of the patients were taking antiarrhythmic drugs at the time of late follow-up, which meant that the actual ablation success was about $50 \%$ in this trial, which is quite low compared with what is reported. So, if correctly reported, the success rate in the pulmonary vein isolation group was less than $50 \%$ at 1 year and just above $50 \%$ in the maze patients.

So how do they compare to other trials? There have been 7 other randomized trials in this area. Now, the great news, including this trial, is that every randomized study has shown that ablation is better than no ablation, and that clearly needs to be our take-home point.

If we take out the one trial that used an ablation technology that is now off the market, the surgical freedom from Afib was lower in the CTSN trial than in any of the previously reported trials, and particularly the ones that used biatrial atrial lesion sets, which were generally in the 80 to $95 \%$ range.

How do they compare to those at experienced centers? I will share with you some data we are going to present in the next session. From our center looking at the prospectively collected but retrospectively analyzed single center trial of patients with mitral valve disease, at one year the freedom from all atrial arrhythmias was over $90 \%$ cumulative. We are going to look at the breakdown between 
degenerative and rheumatic, but it didn't really matter much. The results of Ad and colleagues were similar in 377 patients, which, again, showed at 1 year that the freedom from antiarrhythmic drugs was greater than $90 \% .^{25}$

So, I would have to say that the low success rate in this trial suggests a lack of standardization of the procedure and perhaps a lack of expertise at some centers. And it is important for everyone to know that if you perform the lesion set poorly, it is actually proarrhythmic and could be worse than no lesion set at all.

I would say that if you looked at why the results were so low, if you go to the appendix, $40 \%$ of the ablations in this trial were performed with unipolar radiofrequency (RF), which really has been documented to be an ineffective energy source both in experimental and clinical trials. There is a huge mountain of literature on this, but from a study in Europe, only $20 \%$ of the lesions were transmural. And in fact, in the consensus guidelines, we strongly do not recommend the use of unipolar RF ablation as its efficacy is questionable. If you do use unipolar RF, you really need to do acute lesion integrity testing, which was also another shortcoming of the trial, and that the effectiveness of pulmonary vein isolation in the maze group was only really checked in $55 \%$ of patients and only confirmed in just more than $50 \%$.

So, in conclusion, this is a very important trial, and I do congratulate them for performing it, and it really, I think, clearly establishes the efficacy and safety of surgical ablation in this patient population. I think it really can't be emphasized enough that it wasn't powered to define the efficacy of the different lesion sets, which Dr Gillinov has said. I think it illustrates, again, that in surgical trials the standardization and optimization of techniques are really critical when you examine the efficacy of a specific procedure.

Thank you.

Dr O'Gara. Thank you very much. We are going to move on to the next aspect of our AF studies, "Rate control versus rhythm control for atrial fibrillation after cardiac surgery." ${ }^{26}$ Dr Michael Mack from Baylor Health Care System will be joined by Dr Richard Lee from St Louis University.

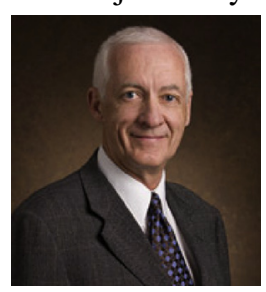

Michael J. Mack, MD. Thank you, Pat. As mentioned, this is a surgical version of the Atrial Fibrillation Follow-up Investigation of Rhythm Management (AFFIRM) trial, which is studying rate versus rhythm control for postoperative $\mathrm{AF}^{27}$ What you will hear is an abridged version of the presentation that Dr Gillinov gave at the American College of Cardiology 5 weeks ago and was published simultaneously in the New England Journal of Medicine.

I have no conflicts relevant to this material.
The purpose of the trial was to determine the effectiveness and safety of rate versus rhythm control for newonset $\mathrm{AF}$ or flutter after cardiac surgery. The criteria for entry was onset of AF during the index hospitalization within the first 7 days after surgery and persisting for more than 60 minutes or having a recurrent episode of $\mathrm{AF}$ or flutter independent of how long it lasted.

The treatment for rhythm control was amiodarone with or without cardioversion as necessary. Cardioversion was recommended if the AF occurred for more than 24 hours after the initiation of amiodarone.

Rate control was at the choice of the treating physicians. It was usually a beta-blocker, although calcium channel blockers or digoxin were also used. The goal was to achieve a target heart rate of less than 100 .

The primary endpoint was the total number of hospital days within the first 60 days of randomization. Counted in those hospital days were visits to the emergency department, short stays, and rehospitalizations. This was felt to be an appropriate surrogate of whether AF was clinically significant after surgery.

The Consolidated Standards of Reporting Trials (CONSORT) flow diagram shows that 2300 patients were enrolled and consented and 1800 patients were excluded because they did not have postoperative AF. Thus, 523 patients were randomized; 262 to rate control and 261 to rhythm control.

This was an intent-to-treat analysis, and approximately $25 \%$ of patients didn't end up receiving the assigned treatment either due to inability to achieve adequate rhythm control or because side effects of treatment, usually with amiodarone. This is about the same percentage as was seen in the AFFIRM trial. Therefore, the primary endpoint analysis was 262 versus 261 patients.

To get an idea of who these patients were, $40 \%$ of the patients had isolated CABG, $40 \%$ had isolated valve repair or replacement, and $20 \%$ had combined repair and replacement. So therefore, the results of this study are generalizable to the majority of patients undergoing cardiac surgery.

The incidence of new onset-postoperative $\mathrm{AF}$ was $33 \%$. It was lowest in CABG patients at $28 \%$, greater in valve replacement, at $34 \%$, and there was an almost a $50 \%$ chance of going into AF if the patient had CABG plus valve procedure.

The number of days in the hospital is not the total postoperative stay but the time from when the patient went into AF and was randomized. It was the same in both rate and rhythm control; five days in rate control, five days in rhythm control. The total number of index hospital days was also the same, and the total number of readmission days was also the same.

There was no difference in complications in either arm, including bleeding, stroke, death or major complications. 


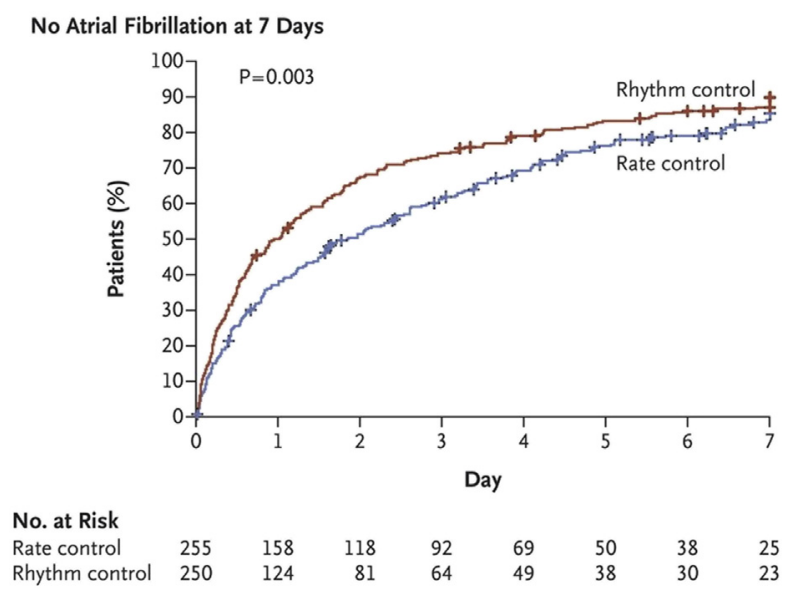

FIGURE 4. Patients with no atrial fibrillation at 7 days. The figure shows the proportion of patients undergoing cardiac surgery who had a stable heart rhythm without atrial fibrillation during the first week after randomization in the rate-control group and the rhythm-control group. From Gillinov and colleagues. ${ }^{26}$ Copyright (C) 2016 Massachusetts Medical Society. Reprinted with permission. http://www.nejm.org/doi/full/10.1056/NEJMoa1602002.

The readmission rate was $18.5 \%$ in patients that went into AF. Specifically, by AF treatment, it was the same in both arms, at $2.6 \%$ and $3.9 \%$ of all patients.

The only difference between the 2 arms was the time to achieve a stable non-AF rhythm. Patients in the rhythm control arm achieved a non-AF rhythm earlier than those in the treatment arm (Figure 4). ${ }^{26}$ However, by 60 days, the number of patients who had non-AF by electrocardiogram were $94 \%$ and $98 \%$, which was significant.

Although it was a statistically significant difference, I don't think it is a clinically meaningful difference, because almost all patients were in either sinus rhythm or junctional rhythm at 60 days.

So, in summary, there was no clear advantage of rate or rhythm control strategy based on an equal number of days spent in the hospital, similar complication rates, and low rates of $\mathrm{AF}$ at 60 days after onset. More rhythm control patients were free of AF compared with rate control, but it was a small difference, and therefore we felt that patient and physician preferences should inform choice.

The clinical inference of this study is that rate control is a reasonable strategy in that it avoids toxicity associated with amiodarone, and the need to institute rhythm control usually is evident during the initial index hospitalization.

So, the unanswered questions are that we don't know the true burden of AF, nor do we know whether it matters; what the predisposing factors are other than the type of operation; and the role of anticoagulation. In the patients that the guideline recommendations were used for anticoagulation, there was no difference in stroke or thromboembolism between those patients that received warfarin and those that did not, although there was a higher bleeding rate in those that did.
So, has this affected early clinical practice? We are now using less amiodarone, especially in elderly patients. We are no longer performing cardioversion as frequently in the hospital unless patients need it for hemodynamic instability or symptoms. We have less reluctance now to discharge patients in AF. And the role of anticoagulation is still individualized based on the patient without clear definitions of what should be done going forward.

Dr O'Gara. Richard.

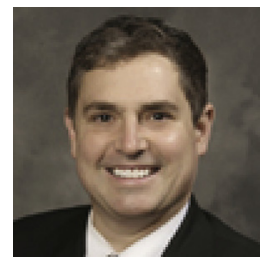

Richard Lee, MD. Thank you for the opportunity. I have no relevant commercial disclosures. However, I must tell you, that I found Marc Gillinov's original slides from the Internet and I modified them. So, I will present their data from a different perspective, but I did get his permission.

I also would like to say that, for starters, we have to appreciate that this is an amazing opportunity that Drs Gillinov, Mack, and the others did a randomized prospective surgical study. For that they deserve not just our recognition but our admiration.

That said, I don't think I can share with you the implications for clinical practice change. I think really the study shows us how we should change research practice, and I will go into why.

So, à la David Letterman, I am going to give you the top 3 revisions that this article should have for the next version of what is inevitable for this study.

No. 3. They need to study isolated CABG alone. Why? Yes, it is true, about one half of the people had CABGs, but half the people had valves. In addition, the valves were heterogeneous. They were aortic, mitrals, tricuspids, and combinations. These are different patients. They are not the same.

And as you saw in the previous discussion, the incidence of postop AF is different in these subgroups. Why? Because the mechanism is probably different. It is probably even different for aortic valve disease and mitral valve disease. Certainly, the implications for AF recurrence are higher in tricuspids.

Moreover, after revision, the authors thoughtfully separated the groups, and what did they find? Well, first of all, recognize that this group is only powered to find a twoday difference in hospitalization at 60 days, and when you look at the CABG valve group, the $P$ value of the primary endpoint is .11, with only 100 patients. I think if you did this study with 500 patients in this group alone, you may find a difference.

Moreover, history of AF was excluded, but no one really looked for it. So, I would challenge you and say that maybe some of these patients had unrecognized AF before the operation and were counted as not having AF.

No. 2. The next study should be powered to evaluate survival and complications. This is from one of Marc's slides 
again. It was not powered to detect differences in stroke or serious bleeding. Again, it was designed to look for a 2-day difference, and the number was 500 patients.

Now, the bleeding rate wasn't significantly different, but was at $83 \%$ greater in the rate control group. The stroke rate wasn't significantly different, but was $300 \%$ greater in the rate control group. And the noncerebral thromboembolism was not significantly different at $200 \%$ greater in the rate control group at 60 days.

No. 1. An on-treatment analysis should be included. It is good that they brought up AFFIRM, and we know AFFIRM had rate versus rhythm control, and at a mean follow-up of $3-1 / 2$ years there was no difference between the 2 arms. Also, though, 1 in 3 of these patients had a seriously disabling stroke, death, or cerebrovascular event.

Nonetheless, the challenge with AFFIRM is the same challenge with this study, the crossover rate. This is intent to treat, which has to be done. But what you do is you have a patient in rhythm control, goes into rate control, and it is counted as rhythm control. If you have a patient in rhythm control, it is counted as rate control.

What about this study? Well, yes, this had a high crossover rate. So, for every 4 patients in the rhythm control arm, one crossed over to rate control and was counted as rhythm. For every 4 patients in the rate control arm, one crossed over to rhythm and was counted as rate.

Why is this important? Well, when you look at AFFIRM, later they did the on-treatment analysis and did a multivariable analysis, and, surprise, what does make sense, the patients who were in sinus rhythm actually had a better survival. This study wasn't powered for this endpoint, but we need to look at it, because just as Dr Damiano said, I would caution you from applying a nonpowered, nonsignificant outcome and putting it in a box and treating your patients differently, because it is just not appropriate yet.

So, for implications for clinical practice, I don't think there are any right now. Not, yet. We do know that most patients end up in sinus rhythm no matter what, so that is good. Over 60 days, there is not much difference in total hospital stay, but when we do a larger study and longer follow-up, we actually may find that rate control is worse.

But as Lao Tzu says, "A journey of a thousand miles begins with a single step." This is a critical, critical first step in understanding the incidence and significance of postop A-fib.

Thank you.

Dr O'Gara. Thanks very much Rick, for those comments. One question is all we have time for. Ralph, you get the question. Please tell us about your institution's approach to postoperative $\mathrm{AF}$ and whether this information has changed your thinking.

Dr Damiano. I would probably say that it hasn't changed our thinking, although I think I completely agree with the initial conclusions of this trial. I mean, similar to the changes that Mike elucidated in his practice were sort of our practice already before the trial.

We are very hesitant. In elderly patients, I think that is a group that amiodarone can have a lot of side effects and you should think about. We have never been aggressive with cardioversion, because I have always felt that the risk of that overcomes any benefit, and this trial may put to rest some of the overuse of that.

It is interesting, and I agree completely, this trial is very hypothesis-generating. It is the most common complication after cardiac surgery today, and you can see from this trial it is incredibly common. And nothing we have done over the last 3 decades, despite numerous randomized trials looking at prophylaxis and trying to prevent it, seems to have really impacted much. So, looking at the treatment side I think is really important.

The one thing that I would be somewhat worried about, and longer follow-up will be needed, is the fact that there are more patients still in AF at 60 days. Everything we know about $\mathrm{AF}$ would suggest from the kind of electrical and structural remodeling from $\mathrm{AF}$, the longer you are in it the worse it is. And one benefit as you go into further studies or bigger studies would be, certainly you would think that you want to get patients back in sinus and stay in sinus sooner the better, and I think that has been shown in a lot of trials.

Dr Ailawadi. And the last comment I guess, just a word of reason in terms of interpreting these results. The conclusion of this trial was that either rate or rhythm control is appropriate. I know Mike and Ralph have given some suggestion as to their approach of a "rate control strategy first." We have taken the alternative approach in the past at our institution, and this study confirms that it is acceptable to have a "rhythm control strategy first" to try to avoid the need for anticoagulation by cardioverting them soon. We use amiodarone liberally but do not cardiovert electrically, which is different from the trial. We feel, in these elderly patients, if we can avoid the need for anticoagulation, ultimately, they might be better off.

Dr O'Gara. Thank you.

Dr Weisel. Thank you very much for interesting insights into the treatment of AF. These are the 2 subjects now we have our final presentations.

First will be Eric Rose from Mount Sinai in New York, who is going to talk to us about the future of the network. Eric is the vice chair of the network and one of the founding members.

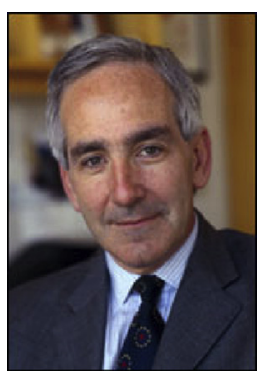

Eric A. Rose, MD. Well, I think it was reasonable to budget this talk for 4 minutes in light of the incredible amount of discussion that the previous talks have generated, so I will try to be brief. But I think it is already clear that this network is stimulating a good deal of thinking and probably an increasing amount of behavior. 
I do have some disclosures to make. Mesoblast provides cells for the randomized mesenchymal stem cell trial in this network; Abiomed has not done a trial with us; and I am the chair of the scientific advisory board of Broadview Ventures, which owned shares in a mitral valve replacement percutaneous company.

Let me talk briefly then about the scope of the network that we anticipate, where it is and where we think it will go; the resources that it requires to sustain the network; the relationships that we have cultivated and need to cultivate; the people that we think we need to attract and grow; and lastly, briefly, the impact.

We started with approximately 8 core centers and have gone now to more than 50 participating institutions in the network, and you will hear about our international plans in the next talk. NIH has supported this network now to the tune of more than $\$ 100$ million committed to it. We have also had significant funding from the Canadian Institutes of Health Research. We do anticipate funding from international funders in the coming years, and we have begun to explore adding commercial partners to trials that we do.

The relationships that we have cultivated now include relationships with registries. We do have an upcoming trial of hybrid myocardial revascularization versus standard surgical revascularization that will be a registry-driven trial in collaboration with the STS.

We have collaborated now with numerous professional organizations on guideline development, in particular the AATS, that we are particularly proud of. That is very recent.

We have great journal relationships and have published extensively, and I must say the relationship with the New England Journal of Medicine I think has been particularly special and important to the development of the network.

Lastly, it has been key to us to have input and collaboration with the FDA, because some of our trials have required and will require investigational device exemptions to get them done, and the FDA has been a good partner to allow us to get approvals for these investigational device exemptions promptly.

Now, let me talk about people, because hopefully more and more of you will get involved with this network. At the lowest but most fundamental level are those who participate, enrollers. It is key for people to get involved with this network who believe in the equipoise that we have and that learn the skills that are required to enroll patients. And for junior faculty members in particular at academic institutions, we are hoping to provide a training ground, and I think we are growing a network of investigators that have these skills that will propel more and more trials.

At another level as people become further involved with the network, and you might call this level 2, they learn how to manage trials, they learn how to analyze trials, they participate in the management of the analysis of trials, and they have become communicators for the trials, both as champions for enrollment and also as champions for spreading the messages and the uncertainties that result from the trials that we have completed and the ones that we have under way.

At a highest level, and you have seen several of our power users, if you will, on this platform today, are the actual trial creators, designers, leaders that already participate in this network and that we believe firmly we are growing for the future of the field.

It is essential that this enterprise, we believe, be managed by a data coordinating center that knows what it is doing, and this data coordinating center has gone through a very steep and profound learning curve but has become remarkably efficient and productive. We have added students and fellows to our portfolio, and we have critical collaborations with biostatisticians, nurse coordinators and monitors.

I think it is worth pointing out that one of the reasons I believe for the high incidence of complications or adverse events that you see in our trial is that we actually have independent study monitors who actually count these events. These are not fly-by-night or unstandardized processes for acquiring the occurrence rates of events.

Let's talk now about the impact. Already I think you can see that, the last speaker perhaps notwithstanding, we believe that we are the source of a growing clinical evidence base that should be continuously refining the standard of care. To say that we have any definitive answers to questions is not our aim, but providing at least some evidence-based answers is.

We also have an enlarging array of trial templates for future investigations. Namely, if you want to plug in a mitral valve trial at this point that you have a question about, we think we can implement the execution of that trial in ways that were not possible prior to the network. And in that way, we provide a very hospitable investigational infrastructure for clinical proof of concept trials, as well for novel approaches, and maybe lesion sets could be the next randomized trial that is addressed, for example, in AF.

Part of our mission and impact I think already is that we are training future investigators and collaborators, and most importantly in the aggregate we have created, we believe, a model for the emerging new era of interventional biology for surgeons, for our medical colleagues and medical professionals outside the field as well.

I appreciate the opportunity to present this today to the Association and am grateful that it has provided this platform for our network.

Thank you very much.

Dr O'Gara. Thank you very much, Eric. And I would like to now ask to come to the podium to close the session Dr Timothy Gardner from Christiana Care Health System in Delaware-for those of you who may not remember, Dr 
Gardner was the inaugural chair of the CTSN - and Marissa Miller, who is our program director at the NHLBI.

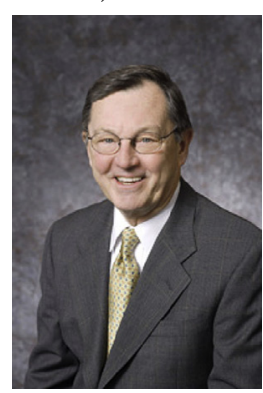

Timothy J. Gardner, MD. Thank you very much. I am going to close with an acknowledgment of the support from our sponsor for this Network, which has been remarkable. Without this support of NHLBI, without all of the influence and importance that that has brought to us, the Surgery Network certainly wouldn't be here today.

Let me just recount the long and distinguished history of cardiac surgery at $\mathrm{NIH}$, starting at the National Heart Institute, which was the forerunner of NHLBI. And if you didn't know Glenn Morrow, you certainly have heard about him, because he and his associates trained 2 or 3 generations of leaders of cardiac surgery. Many young cardiac surgeons were mentored both in cardiovascular research but also, their time at National Heart Institute gave them an outstanding start in clinical heart surgery. Dr Morrow, who had been trained at Hopkins in the golden era with Dr Blalock, went to Bethesda and started the surgical program at the National Heart Institute. He worked, interestingly, with Dr Braunwald, who was his cardiology counterpart, and with Dr Nina Braunwald, who was one of the first women in cardiac surgery and passed away early in her surgical career from an unfortunate premature illness.

Dr Morrow's era at the NIH was very influential to our specialty. He was succeeded by Dr Richard Clark, who was a leader in the STS and a founding director of the STS national database. But the surgery branch did not continue in the Morrow tradition and was actually closed around 1980, and that next decade was a very quiet period for cardiac surgery at NIH.

And then in 1999 Dr Elizabeth Nabel joined the NHLBI from the University of Michigan as scientific director of clinical research and subsequently served as the Institute Director. We heard from her successor, Dr Gary Gibbons, yesterday. The importance and the influence of NHLBI on progress on cardiovascular medicine was well brought out in his address.

But Dr Nabel was instrumental in restoring the cardiac surgery presence at NHLBI. In 2004, she brought cardiac surgery back into the clinical program at NIH. She appointed Keith Horvath, who many of us know and who was trained under Larry Cohn at the Brigham and Women's Hospital. Keith serves as chief of the NIH Heart Center at Suburban Hospital near the main campus of NIH, and he is also the director of the Intramural Cardiothoracic Surgery Research program.

Restoring a cardiac surgery presence at NHLBI was significant. In 2000, she hosted a symposium on current advances and challenges in cardiac surgery. It was her first effort to have surgeons back at NHLBI talking about advances in our field and what were our needs. Her co-host for this symposium was Larry Cohn, President of the AATS at the time.

She also encouraged and reinvigorated collaboration between cardiac surgeons and the extramural division, which is the division that supports research programs around the country. I worked with Dr Alice Mascette, a cardiologist in the extramural Division at the time, who led the efforts of restoring a formal presence for cardiac surgery in the extramural program.

There was an interesting workshop on neurocognitive changes after cardiac surgery in 2003, and then in 2004, there was a Working Group on the future directions in cardiac surgery. NHLBI also considered sponsoring multicenter clinical trials, including a study to compare outcomes with conventional versus off-pump CABG surgery. But the principal recommendation from that Cardiac Surgery Working group was to establish a CTSN that would support multiple multicenter trials, as was being conducted in other NHLBI-supported networks such as the Pediatric Heart and Heart Failure networks.

Dr Nabel became the NHLBI Director in 2005. She established the advanced technologies and surgery branch in the extramural program and recruited Dr Marissa Miller, who has led that branch and has really been the principal collaborator, supporter and friend at NHLBI since then.

As you know, the CTSN started in 2008. Pat O'Gara was appointed co-chair and has been an important leader for the network.

In 2011, Dr Miller and NHLBI with the AATS co-hosted a symposium that, again, has provided important direction and support for the network. And then, in 2013, NIH support for the clinical trials network was renewed for a second 5 -year term

So, I am going to turn over this portion to Dr Marissa Miller, who, as I said, is our representative, supporter, and friend at NHLBI.

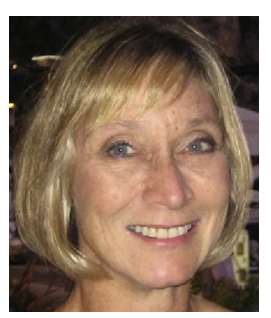

Marissa A. Miller, DVM, MPH. I would like to thank the Association for this invitation and, more importantly, for this opportunity to discuss the findings from these important trials with the broad cardiac surgical community.

I was reminiscing a bit, like Tim, who was our first study chair and helped us get going with the network, about a meeting here 10 years ago when we did a presolicitation discussion with cardiac surgeons about this network that was being formed and the opportunity to make the application with us.

So NHLBI made the decision to move forward to support cardiac surgical clinical trials using the network model, 
which is a common model for us, because, and I think that we have shown today, it has created a community of practice with a common purpose. We have certainly extended our collaborations extensively. We have been able to leverage resources across many centers, both of funded sites and beyond that.

We have established an efficiency that has come from a standard way of conducting trials and standard formats for collecting information that I think has helped us to get where we are today in terms of completing trials. And as has been demonstrated, we have been able to complete a number of ultimately high-impact trials.

The network model also allows flexibility for rapid startup and rapid closure; and fortunately, this network has not had to make that important and difficult decision to close a trial.

So, what have we learned? Beyond the important clinical findings, I think that we have learned a lot about conducting collaborative clinical trials. The first "a-ha" moment was, maybe it sounds obvious now, but we thought, well, cardiac surgical trials, if we design them in such a way, it is an encapsulated activity. It certainly is not. It involves many others within the continuum of care of patients, including, very, very importantly, cardiologists. We had to rethink some of our trials, and I think we have benefited from involvement from neurologists and cardiologists and have had to even go out to referring physicians in terms of identifying patients for our trials.

Equipoise has already been mentioned today, but it is not just equipoise of the cardiac surgical investigator. We found that it extends to the patient and sometimes to the institution and most certainly to referring physicians. So, this is a critical concept when you are conducting trials of this type.

We have instituted a best practice, which is an early screening $\log$ within the network, which is to figure out what patients are truly eligible within our trials, and then adjusted our conduct accordingly.

Staffing is critical. I think we found that it really takes more than just the staffing level that is provided in the grant awards, and institutions have stepped up to provide the additional funding and, particularly, coordinator support necessary. It does take a village, and that includes active involvement from the sponsor.

NHLBI has truly enjoyed going out for site visits, to help work with sites, to optimize operations, and that seems to have benefited the network broadly.

And more is better, and as you have seen, we have more and more collaborating sites, and I will speak to this in a moment. Having a robust and engaged infrastructure allows the conduct of a spectrum of trials.

I don't need to go through this again, just to point out that in the time now, this experiment has gone on 9 years and the CTSN has completed 5 randomized clinical trials and a large observational registry. They have been recognized at large national meetings and published in high-impact journals. We are grateful for this success, which is a tribute to the entire team involved in CTSN including the investigators, collaborating core laboratories, and sites

If you have ideas, you can come to any one of the Principal Investigators, the DCC, or myself, with trial concepts, substudies and so forth.

So, I mentioned that the concentric circles of collaboration are moving out, and our thanks to Richard Weisel for engaging a consortium of sites within Germany that are now committed to collaborate with us. They are coming with their own funding and their own ideas that have already helped to optimize the TR protocol and hopefully more trials in the future. So, we are looking forward to that collaboration.

How do we keep going, because hopefully everyone here feels that this is worthwhile, this network is value added, and there are more questions in the cardiac surgical realm to be answered in a collaborative way.

The obvious metric that NHLBI and the other sponsors will be looking at is, has the network designed and completed rigorous clinically relevant trials? Thank you for the feedback today; it is very important to us. Have we been able to involve the professional societies and engage the community? We are trying and we want more of that, so come to us with your ideas.

We have 3 skills cores, clinical investigator skills cores in which we are developing young scholars. That is a very important value to NHLBI, and I think will benefit the entire community long term in terms of the succession of clinical trials that are run in cardiac surgery.

Eric has talked about sustainability issues. In addition to European collaborators, we are looking to industry as well and others.

And most importantly, we want to demonstrate impact, and this is where you can really help us. Gorav did mention that we want to look at the STS database information to see whether our trials have changed practice patterns. If you have other ideas and you want to engage with us on this point, please come speak to us. Again, we want to show that there are new smart minds involved in clinical research, particularly younger investigators and we hope to expand beyond our initial small number of sites.

We always keep an eye towards innovative trial designs, adaptive designs, listening to the FDA, considering broad NHLBI input and scientific community feedback.

That is the scope of what we need to show and do to make a strong case within the institute for additional funding. This is my contact information. I am happy to speak with any of you that have questions at a later time.

Thank you.

Dr Weisel. Thank you very much, Marissa, and this completes our session. The meeting is now adjourned. 


\section{Conflict of Interest Statement}

Authors have nothing to disclose with regard to commercial support.

\section{References}

1. Ascheim DD, Gelijns AC, Goldstein D, Moye LA, Smedira N, Lee S, et al. Mesenchymal precursor cells as adjunctive therapy in recipients of contemporary left ventricular assist devices. Circulation. 2014;129:2287-96.

2. Gelijns AC, Moskowitz AJ, Acker MA, Argenziano M, Geller NL, Puskas JD, et al. Management practices and major infections after cardiac surgery. J Am Coll Cardiol. 2014;64:372-81.

3. Coronary artery surgery study (CASS): a randomized trial of coronary artery bypass surgery. Survival data. Circulation. 1983;68:939-50.

4. Cobb LA, Thomas GI, Dillard DH, Merendino KA, Bruce RA. An evaluation of internal-mammary-artery ligation by a double-blind technic. $N$ Engl $\mathrm{J}$ Med. 1959;260:1115-8.

5. EC/IC Bypass Study Group. Failure of extracranial-intracranial arterial bypass to reduce the risk of ischemic stroke. Results of an international randomized trial. $N$ Engl J Med. 1985;313:1191-200.

6. Sundt TM Jr. Was the International Randomized Trial of Extracranial-Intracranial Arterial Bypass representative of the population at risk? N Engl J Med. 1987;316:814-6.

7. Bannister CM. Letter to the editor: extracranial-intracranial arterial bypass. $N$ Engl J Med. 1986;314:1192-3.

8. Plum F. Extracranial-intracranial arterial bypass and cerebral vascular disease. $N$ Engl J Med. 1985;313:1221-3.

9. Haynes RB, Sackett D, Taylor DW, Barnett HJM, Peerless SJ, Hachinski VC, et al. Response to the Letter to the editor: extracranial-intracranial arterial bypass. N Engl J Med. 1986;314:1192-3.

10. Freedman B. Equipoise and the ethics of clinical research. N Engl J Med. 1987; 317:141-5.

11. Smith CR, Leon MB, Mack MJ, Miller DC, Moses JW, Svensson LG, et al; PARTNER Trial Investigators. Transcatheter versus surgical aortic-valve replacement in high-risk patients. N Engl J Med. 2011;364:2187-98.

12. Jones RH, Velazquez EJ, Michler RE, Sopko G, Oh JK, O'Connor CM, et al. STICH Hypothesis 2 Investigators. Coronary bypass surgery with or without surgical ventricular reconstruction. N Engl J Med. 2009;360:1705-17.

13. Ghali JK. Surgical ventricular reconstruction. N Engl J Med. 2009;361:529.

14. Nishimura RA, Otto CM, Bonow RO, Carabello BA, Erwin JP III, Guyton RA, et al; American College of Cardiology; American College of Cardiology/American Heart Association; American Heart Association. 2014 AHA/ACC guideline for the management of patients with valvular heart disease: a report of the American College of Cardiology/American Heart Association Task Force on Practice Guidelines [published correction appears in J Thorac Cardiovasc Surg. 2014;64: 1763]. J Thorac Cardiovasc Surg. 2014;148:e1-132.
15. Acker MA, Parides MK, Perrault LP, Moskowitz AJ, Gelijns AC, Voisine P, et al; CTSN. Mitral-valve repair versus replacement for severe ischemic mitral regurgitation. N Engl J Med. 2014;370:23-32.

16. Goldstein D, Moskowitz AJ, Gelijns AC, Ailawadi G, Parides MK, Perrault LP, et al. Two-year outcomes of surgical treatment of severe ischemic mitral regurgitation. N Engl J Med. 2016;374:344-53.

17. Michler RE, Smith PK, Parides MK, Ailawadi G, Thourani V, Moskowitz AJ, et al. Two-year outcomes of surgical treatment of moderate ischemic mitral regurgitation. N Engl J Med. 2016;374:1932-41.

18. Smith PK, Puskas JD, Ascheim DD, Voisine P, Gelijns AC, Moskowitz AJ, et al. Cardiothoracic Surgical Trials Network Investigators. Surgical treatment of moderate ischemic mitral regurgitation. N Engl J Med. 2014;371:2178-88.

19. Fattouch K, Guccione F, Sampognaro R, Panzarella G, Corrado E, Navarra E, et al. POINT: Efficacy of adding mitral valve restrictive annuloplasty to coronary artery bypass grafting in patients with moderate ischemic mitral valve regurgitation: a randomized trial. J Thorac Cardiovasc Surg. 2009; 138:278-85.

20. Chan KM, Punjabi PP, Flather M, Wage R, Symmonds K, Roussin I, et al; RIME Investigators. Coronary artery bypass surgery with or without mitral valve annuloplasty in moderate functional ischemic mitral regurgitation: final results of the Randomized Ischemic Mitral Evaluation (RIME) trial. Circulation. 2012;126: 2502-10.

21. Rutherford JD, Pfeffer MA, Moyé LA, Davis BR, Flaker GC, Kowey PR, et al. Effects of captopril on ischemic events after myocardial infarction. Results of the Survival and Ventricular Enlargement trial. SAVE Investigators. Circulation. 1994;90:1731-8.

22. David TE, Armstrong S, McCrindle BW, Manlhiot C. Late outcomes of mitral valve repair for mitral regurgitation due to degenerative disease. Circulation. 2013; 127:1485-92.

23. Cardiovascular Outcomes Assessment of the MitraClip Percutaneous Therapy for Heart Failure Patients with Functional Mitral Regurgitation (COAPT) trial. ClinicalTrials.gov Identifier: NCT01626079. Available at: https://clinicaltrials. gov/ct2/show/study/NCT01626079.

24. Gillinov AM, Gelijns AC, Parides MK, DeRose JJ Jr, Moskowitz AJ, Voisine P, et al. Surgical ablation of atrial fibrillation during mitral-valve surgery. $N$ Engl J Med. 2015;372:1399-409.

25. Ad N, Henry L, Hunt S, Stone L. The implementation of a comprehensive clinical protocol improves long-term success after surgical treatment of atrial fibrillation. J Thorac Cardiovasc Surg. 2010;139:1146-52.

26. Gillinov AM, Bagiella E, Moskowitz AJ, Raiten JM, Groh MA, Bowdish ME, et al. Rate control versus rhythm control for atrial fibrillation after cardiac surgery. N Engl J Med. 2016;374:1911-21.

27. Saksena S, Slee A, Waldo AL, Freemantle N, Reynolds M, Rosenberg Y, et al. Cardiovascular outcomes in the AFFIRM Trial (Atrial Fibrillation Follow-Up Investigation of Rhythm Management). An assessment of individual antiarrhythmic drug therapies compared with rate control with propensity scorematched analyses. J Am Coll Cardiol. 2011;58:1975-85. 